\title{
I Cannot Treat Stupidity: The Function of Divination in Planning and Managing Life Crisis within the Dagbong Traditional Society in Northern Ghana
}

\author{
Salifu Abukari*, Habibu Issah, Yussif Hamdan Adam \\ University for Development Studies, Tamale, Ghana \\ Email: *a.salifu@uds.edu.gh
}

How to cite this paper: Abukari, S., Issah, H., \& Adam, Y. H. (2022). I Cannot Treat Stupidity: The Function of Divination in Planning and Managing Life Crisis within the Dagbong Traditional Society in Northern Ghana. Open Journal of Social Sciences, 10, 420-439.

https://doi.org/10.4236/jss.2022.101032

Received: November 10, 2021

Accepted: January 24, 2022

Published: January 27, 2022

Copyright $\odot 2022$ by author(s) and Scientific Research Publishing Inc. This work is licensed under the Creative Commons Attribution International License (CC BY 4.0).

http://creativecommons.org/licenses/by/4.0/ (c) (i) Open Access

\begin{abstract}
Diviners play key roles in deciding individuals' decision-making processes among the indigenous peoples of Africa and in many other parts of the world. One key decision that people make has to do with the pursuance of good health. The purpose of this study was to explore the common types of diviner practices undertaken by the Dagomba, identify disease causative agent among Dagomba, and explore the rationale behind the practice of divination. The goal of this paper was to explore the function of divination in planning and resolving life crises within traditional Dagbon communities in Ghana. The investigation was guided by Rational Choice theory. In all, a total of 73 participants were sampled using snowball and purposive sampling techniques for both the in-depth interviews (33) and focus group discussions (40). The in-depth interviews included 25 diviners chosen from 5 communities in Yendi Municipality and its surrounding communities including 8 health workers, while 40 community members selected from the 5 communities $(8$ members per community)-both male and female-participated in the focus group discussions. Structured observation was also employed to gather additional information to supplement the data collected through other methods. Responses were captured using tape recorder (field notes were also taken) and afterwards transcribed and coded. Analysis was performed using thematic content analysis. The study discovered various types of diviner practices among Dagomba. It also found that most people use divination as diagnostic tool to determine the cause of ailments and diviners play important role in determining the cause and management of illnesses in the study communities. It was further established that most patients combined both divination and allopathic medicine in seeking answers to their health problems. This is
\end{abstract}


due to their conviction that many ailments have both spiritual and physical elements that must be attended to concurrently. It was further discovered that certain disorders and illnesses necessarily require diviner consultation in order to decide the best course(s) of action to cure or prevent it from getting exacerbated. However, some of the diviners indicated their inability to treat all maladies, stating for example that they could not treat ignorance and stupidity. Soothsaying, AfalMallam, Jinwariba, Gbanigba consultations among others, are among the common diviner services regularly patronized by traditional Dagbon communities, according to the study. Going by these world views, the indigenous Dagomba person sees the practice of divination as a vehicle they can use to confront life crises, hence our study recommends that divination be merged with allopathic medical care methods so as to provide holistic health care services to all who may need it.

\section{Keywords}

Divination, Soothsaying, Spiritual Illnesses, Yal'kura, Witchcraft, Nantoo

\section{Introduction}

Divination is a popular phenomenon that is practiced by many societies across Africa. Divination helps people to make better decisions, create better relationships with less stress. Nukunya (2013) accounted for many conditions divination may be required in traditional civilizations for purposes such as determining the origin of sicknesses, locating a misplaced item, wishing for success, and gathering any knowledge that may be useful to a customer. Illnesses are worldwide phenomena however, the way treatment is sought for these illnesses varies from society to society. For example, many people treat their ailments with mainstream medicine, while others treat their illnesses by invoking supernatural powers, and still, others combine both ways (Senah, 1992). Most traditional African civilizations believe that certain illnesses are caused by supernatural forces and cannot be treated through the use of authodox medicine, necessitating a supernatural approach to treatment (Nukunya, 2013). For example, according to Fratkin (2004), diviners provide counseling services for determining sources of disasters and catastrophes among Pastoralists in Kenya.

Annus (2010) defines divination as a system of collecting knowledge to forecast the reasons for misery, whether present, past, or future, and strategies to revoke such causes in order to ameliorate one's fortunes (Annus, 2010). According to Meyer (1999), divination is a belief in supernatural and invisible powers through which a person can achieve health, honor, prosperity, or other pleasures. Divination is an effort to obtain vision into a question or a circumstance by applying occult methods, a systematic process, or a ritual (Ngutor, Lumun, \& Terwase, 2013: p. 10). It is a methodical procedure of organizing what appears to be unorganized so that they (diviners) can supply solutions to diffi- 
culties. Divination is socially oriented and ritualistic, usually in a religious context. Divination is widely used as protective/preventive medicine in some societies and is widely sought by individuals such as barren women, warriors, people with strange diseases, and others who suspect that their ordeals were orchestrated by their enemies who tried to harm them through witchcraft, sorcery, or spirit possession.

Many ailments linked to the supernatural cannot be experienced or witnessed with the naked eye in many societies. Because such maladies are the result of witchcraft or sorcery, they have spiritual overtones. As a result, there is a widespread perception that illnesses whose genesis necessitates the use of diviner services to mediate between the patient and supernatural forces cannot be treated biomedically. Traditional medical practice among the Dagomba exemplifies a systematic structure prevalent in many societies (Bierlich, 1994). Spiritual mediums are used in many countries to maintain healthy relationships between humans and the spirits of deceased ancestors. Those who are capable of talking with such spirits would generally fall into trance when about to engage them; the spirit is said to explain troublesome issues and what must be done to placate it (Imperato, 1976). Often, diviners would indicate to their clients the source of their ailment. The source could be neglect or violation of ancestral or spiritual underpinning (Azongo \& Yidana, 2015) that tends to haunt the victim. Divination is a method of gaining information from supernatural creatures regarding hidden and/or future desires. Its goal is to "grasp" the hidden realm of spirits and ancestors by linking it to the apparent world of contemporary humans (Fortes, 1987).

A Dagomba's private life is affected by the philosophy and ideas of traditional religious beliefs, which express belief in a wide range of supernatural phenomena. The Dagomba believe in and practice magic (Tim/Tima Malibu) and occultism, and their polytheistic beliefs do not contradict their belief in the one Supreme Being who is claimed to be the creator of the cosmos. The Dagomba also believe in supernatural beings capable of influencing people's lives and determining their fate (Awalu, 2009). The supernatural is an element of Dagomba's social life. The belief in the existence of supernatural forces shapes the worldview of a Dagomba, as it does the worldview of any other ethnic group in Ghana.

In terms of seeking the root cause of illness, the Dagomba are similar to several other ethnic groups. According to Nyabwari (2014), witchcraft, sorcery, and magic are cultural practices utilized in Haiti to influence the transfer of power, resources, and riches. Witchcraft, sorcery, and magic, according to Nyabwari (2014), are security mechanisms used by Haitians to ensure their survival and protection in society. According to them, these phenomena are also employed as a diagnostic technique to assess whether their clients' misfortunes and fortunes are the consequence of supernatural activities through divination. There is no doubt that the Dagomba visit diviners when medicine fails to provide a cure and when a more in-depth explanation for the source of life crises is required 
(Oppong, 1973). However, it is unclear to what degree this is employed to address evident life crises and whether diviners are able to offer solutions or therapy to all life crises. This study was meant to investigate the function of divination in the management and resolution of life crises among the Dagomba in Ghana's Northern Region.

\subsection{Definition of Key Concepts}

Alizini: A spirit that cannot be seen by the average person.

Bag'yuli: Beliefs and activities related with ancestor worship.

Yal'kura: Every Dagomba is supposed to have at least one vocation.

Yogu: Anthrax.

Nar'li: All types of boils.

Sogu: Sorcery.

Nantoo: Some claim it resembles a winged creature, while others think it resembles a reptile. It's mostly connected with illnesses and deaths.

\subsection{Contribution to the Field}

The study has helped in unearthing information that shapes the health-seeking behaviour of the indigenous Dagomba people, including the importance they attached to divination as a way of accessing comprehensive health care for individuals and their families. This understanding has helped in providing input that can be used to design intervention to address practices that are seen to be outmoded and inimical to the health and wellbeing of the people. Again, the study can help in creating opportunities for health educators to design health education and promotion programmes, specifically geared toward diviners and their clienteles for purpose of improving population health more generally.

\subsection{Theoretical Framework}

The rational choice theory was applied to guide and explain the processes involved in health seeking behavior or in selecting therapeutic options. The rational choice theory is motivated by the belief that humans are homo economicus, and that they orient their activities toward what they perceive to be the most desirable means of achieving their goals (Homan, 1974). People weigh various means and purposes in the face of limited resources and select best options amongst them. As a result, the term "rational choice" was coined. The exchange hypothesis is connected with rational choice in sociology. As a result, in healthseeking activities, people chose diviner services over conventional services based on the satisfaction they expect to obtain from such services, or they may have sought both services at the same time depending on personal assessment made (Homan, 1974).

The rational choice theory of social interaction is viewed by the exchange theory as the exchange of real or intangible goods and services. According to Homan (1974), people choose to participate in an exchange after weighing the 
costs and benefits of several options and selecting the most desirable of them. Homan (1974) explained social exchange theory by relating it to the fundamental principle of human activity known as small group behavior. Homan defines elementary behavior as behaviors that occur and reoccur whether or not people prepare for them this sits well with Oppong's (1973) assertion that the Dagomba consults diviners for every imaginable event. Homan connected basic social behavior to individual psychology and motivation. By this, he implies that the fulfillment of social phenomena is fundamentally psychological, and that psychological principles are the fundamental building blocks of explanations for all social phenomena (Homan, 1974).

\section{Methodology}

\subsection{Study Setting}

This study was conducted in the Yendi Municipality of Northern Region, Ghana. The Municipality is the traditional capital of the Dagombas and the residence of the kingdom's King (Yaa-Naa). Despite the prevalence of Islam, the majority of communities and people are mainly traditional. Subsistence agriculture is the people's main occupation, and traditional ways of domestic relationships dominate their life-thus, predominantly the communities are patriarchal.

\subsection{Research Design and Sampling Technique}

The study design was qualitative using ethnographic approach and implemented in Northern Region of Ghana from June to August 2016. In all, 25 diviners were recruited into the study from 5 communities in the Yendi and its environs using snowball and purposive sampling techniques. The recruited diviners were subjected to in-depth interviews in order to better understand their role in traditional Dagomba health-seeking behaviors. Structured observation was also employed. In addition, 40 community members (key informants) were selected for FDGs to explore their views on divination and the role it plays in their health seeking behaviours among the Dagombas.

\subsection{Study Participants}

The study participants included the diviners, community elders, health professionals, and key informants. To have been included in the study, a diviner should have stayed in community for at least 7 years and be a current practitioner of divination. Community members were also expected to have lived in the community for three years or more and to be familiar with the cultural and social norms of the community. It was the considered opinion of custodians of the tradition that 7 years practice as a diviner was enough to enable a diviner to acquire the needed skills, knowledge, norms, values, folklore and the history of the community to practice his/her profession. The research was conducted using the predominant language (Dagbani) of the people and later translated in to English upon exit from field. 


\subsection{Data Collection Tools}

The interview guide with identified themes was utilized to guide the in-depth interview sessions with diviners and key informants, while the focus group discussions guide was also used to extract information from community members. Five focus group discussions (FGDs) that were held in the selected communities included both male and female as participants. Subjects or patients who had been treated and discharged by diviners were also interviewed. 40 to $50 \mathrm{mi}$ nutes was used for each in-depth interview and FGDs, and these sessions were recorded, later translated and transcribed in to the English language. Field notes and structured observations were also employed in the data collection process.

\subsection{Data Analysis}

Data was analyzed by transcribing field-recorded information. Following transcription, the data was uploaded to the NVIVO platform and thematically analyzed. This was accomplished by meticulously scrutinizing the data in order to uncover common themes-that is, concepts, topics, and patterns of meaning that repeatedly emerges (Clarke \& Braun, 2018). The analysis was thus carried out in accordance with Clarke \& Braun (2018) and Clarke et al. (2019)'s six-step approach, which included familiarization, coding, generating themes, reviewing themes, defining and identifying themes, and reporting (Clarke \& Braun, 2018; Clarke et al., 2019). The NVIVO 10 software was used in the analysis.

\subsection{Rigor}

This study used Lincoln and Guba's Evaluative Criteria (Braun \& Clarke, 2014; Aydin \& Aktaş, 2021) to assess data accuracy and reliability, including credibility, dependability or trust, conformability, and transferability. 1) For credibility, interviews were always performed actively and with appropriate time provided. 2) Experts in the relevant field were contacted during the preparation of the semi-structured interview form and data analysis to ensure dependability. 3) Two experts were engaged about the suitability of primary and subthemes for conformability. 4) To ensure transferability, the snow-ball sampling method was utilized to collect data from a suitable sample, with maximum diversity taken into account (Braun \& Clarke, 2014). At the end of each interview, participants were informed that they would be debriefed on transcripts for member checking after the data had been transcribed.

Kumekpor (2002) found that when attempting to apply ethical techniques in social science research, various tough challenges arise. One of them he claims is whether conducting secret study is a smart idea. According to Kumekpor (2002), covert research is suitable and important for gaining a thorough grasp of a social phenomenon. Conducting studies on the social lives of drug dealers, drug users, and prostitutes is one example. Hence, participants were promised of secrecy and given the option to participate or not participate. 


\section{Results}

\subsection{Types of Diviners}

It became evident from the data collected and analyzed that; diviners consisted of varied class of practitioners. The fieldwork had helped in identifying the different types of diviners in practice among Dagombas to include Soothsayers, Afanima or Mallams, Jinwariba, and Gbanigba. The study included all these diviners because of its orientation. A detailed expatiation of these different classes of diviner practitioners and what they do in reality are given below.

\subsection{Soothsaying}

According to the diviners, this type of practitioner works with tools such as the diviner stick (bag-doli), calabash (bag gmani ), bag (bag koligu) and diviner items ( $\underline{\text { bag bihi }}$ ) to foretell or reveal the hidden truth related to a particular phenomenon. Regarding how individual acquires the art of soothsaying, a discussant in a focus group discussion has this to say:

"The art of soothsaying is considered sacred among Dagomba diviners. The soothsaying practice is not acquired; they are called by the ancestors. In most of the soothsaying practices, no one decides to become a soothsayer at will. One becomes a soothsayer through inheritance. When the person who is called or chosen by the ancestors becomes an adult, hel her may be afflicted by certain strange illness and in the process of treating him/her, a soothsayer is consulted to find the cause of the ill health. When it is established that hel she has been chosen, rituals are prepared for such person otherwise hel she will not recover from the ill-health".

This was supported by the sayings of some of the diviners as follows:

"Soothsaying is not acquired by an individual, rather it is a calling by the ancestors or the gods of a family. The person who is called by the ancestors normally falls in trance or exhibits some abnormal characteristics such as mental illness, spirit possession, and unusual illnesses. This may prompt the family head to consult their ancestors through divination to find the cause of the abnormal behaviour of a family member. Through such investigations, it may be revealed to them that the person has been chosen by the ancestors to become a diviner. This will only happen when a diviner in the family dies and it is inherited either matrilineally or patrilineal'.

After it is determined that a person has been chosen, it is the responsibility of the family to set a date for the performance of requisite ceremonies. The rituals include shaving the neophyte's hair and giving him/her a spiritual bath; slaughtering a goat and skinning it without perforating the skin; putting pepper into the neophyte's nostrils to enable him to perform his role as a diviner; setting fire at night and dancing around it with the neophyte; singing spiritual, preparing special food the next day and invite people to feast and wish the neophyte well. In a focus group discussion, one participant stated:

"The neophyte will then be given to an old diviner to teach him the art of di- 
vination using the stick and the other items. The items used in divination such as pieces of iron, cowry shells, stones, seeds, materials of different colors, etc. have their meanings and representations in real life situations. An older diviner will teach the new entrant how to use these things. Here, there is no specific number of years for training given to the neophyte. It all depends on how fast he learns the trade and be able to use the designated items for divination. Some may take a year, others may take two or more years to learn and practice".

The discussant further mentioned that there is no set charge for apprenticeship because it is a call to service from the ancestors. However, to show gratitude to the master-diviner, the neophyte's relatives occasionally give food items and visit the trainer on a frequent basis during the training session. The trainer does not camp the neophyte instead, he stays at home and visits the trainer at set times for training exercises, particularly during divination seasons. During the training sessions, the novice observes the master recite the names of the ancestors, gods of the land, spirits, and sometimes the herbs he employs to treat various maladies. Aside from observation, the neophyte is instructed to do specific activities for the master to evaluate. If the master believes he performed well, the master will summon his colleagues' diviners and, in a special ceremony, they will commission the neophyte into the service of divination.

\subsection{The Afanima/Mallamic Divination}

This type of divination began with the entrance of Islamic religion into Dagbang. According to Bierlich (2007), Islam was introduced to Dagombas by Mallam Mahama Matazu in 1686 during the Yaa-Naa Gariba period. Since then, Islam has spread and influenced Dagomba social life to the point where mallams rule over social events and ceremonies like naming ceremonies, funerals, and other big events.

The hiring of mallams as priests and scribes by Dagbang's paramount chiefs to oversee the recording of occurrences and to pray for peace in their villages was the beginning of this kind of divination. The mallam begins by reciting Quranic texts before moving on to "sand reading." Sand reading is a procedure in which the diviner utilizes sea sand, writes verses of the Quran/Arabic alphabets on it after a client has told the diviner about his or her issues, and the diviner is able to predict or foretell the client the problem presented and the likely solutions based on the pattern developed from sand reading. Clients are occasionally asked to place their palms on the sea sand spread on white calico, and the marks on the palm are interpreted to the client by the diviners. Alternatively, the mallam may use cowry shells instead of the sea sand to predict past, present, and future events that are likely or unlikely to happen to clients. Following the sand reading, the Afa will advise the client on various sacrifices and rituals to perform in order to either banish misfortunes or pave the way for success.

A participant offers the following account about how this style of fortune telling came to be practiced. 
"The Afa divination is not inherited neither is it a call by the ancestors. This type of divination is acquired through learning the Quran and Sufism from a seasoned Muslim cleric who uses the Quran to practice divination. Here, a neophyte is trained through the reading of verses of the Quran and their interpretations. It can take a neophyte 3 to 10 years to acquire the knowledge before practice. This type of divination is as a result of the introduction of the Islamic religion in Dagbon".

Cowries are used in the consultation process by some Afa diviners in this area of practice, and the number of cowries used varies from diviner to diviner. Some can only use four cowries, while others can use between 100 and 256 or 285, depending on the Afa's potency. At times, the Afa diviner will blend the approaches-i.e., soothsaying with the Afa's approach-to providing services to clients. As a result, when solicited for their services, the diviner may want to find out from clients if they prefer the Afa technique, soothsaying, or both. Following the divination session, you may be requested to write some Quranic verses in order to prepare some mixtures for clients to consume, bathe with, or wash the vital parts of their bodies. Talismans and other charms are also made for clients on a case-by-case basis for protection.

\subsection{Jinwariba}

The spirits or ancestors call or choose this type of diviner from a family. It makes no difference what age the individual is. It is opined that once a person is called, he or she begins to see beings such as dwarfs, spirits of various kinds, spirits of deceased relatives, and the ability to capture witches and wizards.

A Jinwara (single) has this to say during an in-depth interview regarding Jinwariba (plural).

" $A$ Jinwara is call by the ancestors or spirits and further confirmed through consultation. When a person is chosen, helshe begins to see abnormal things. Here, the chosen person is initiated in to the profession through rituals. After the ritual, the neophyte is attached to a master Jinwara to teach him how to practice the Jinwariba divination".

Regarding how long a time it takes for the neophyte to gain mastery of art of Jinwara and the ensuing practices, one of them has this to say:

"It can take five to ten years to become knowledgeable in the practice. Our powers are associated with spirits and the cultic practices and we assess ourselves to be more powerful than the others. However, in the course of our practice we also use cowry shells, stones and blood encrusted horns purported to contain the spirits of the Jinwara. During sessions with clients, it is the spirits that talks, after foreseeing the problems the client comes with and we then interpret this to the client".

It was stated that the client may hear the voices of the spirits conversing but may not be able to make sense of it, thus the Jinwara must interpret for the client. Following the divination sessions, the diviners will also prescribe sacrific- 
es for the client to complete. Again, the diviners may offer preventative medication to ward against danger and foes, or they may wish for wealth in life.

\subsection{Gbanigba}

It is a form of divination in which practitioners use Juju (occultic practice) and neili (clairvoyance) in their line of work. According to the diviners, the individual practicing Gbanigba seeks Juju and, once found, travels to the soothsayer in search of spiritual knowledge and understanding to conduct this art of divination. As one participant in a focus group discussion put it:

"The Gbanigba diviner acquires his profession through individual efforts. They are not real diviners. They combine both the soothsayer activities and other magical prowess to perform wonders. The Gbanigba diviner goes to a soothsayer to seek spiritual guidance and then use it to perform their profession".

These particular practitioners are able to "see" the hidden and secrete problems/challenges clients are confronted with and for which they sought immediate solution. In their practice of the art, they also use alizin nima (air spirits). They are able to chant to invoke their presence, and to intervene when they (diviners) are called to duty. In an in-depth interview with one of them, has this to say in this regard:

"...the spirits when at work, speak in tongues, a language that is very hard to decipher by the ordinary person...".

\subsection{Combination of Divination (Traditional Healing) and Orthodox Treatment for Ill Health}

Patients tend to attribute their illnesses to both physical and spiritual forces, hence the combination of different treatment options for purposes of finding remedy to their predicaments. During an in-depth interview, some healthcare professionals intimated that family members of their clients occasionally come to the facility with various substances or objects such as talismans, Rukiya water (spiritual water), and various concoctions and either openly or covertly give it to their relatives (patients) to drink and bathe with. The following is a story told by a healthcare professional about how people use both diviner and traditional medicine to heal themselves.

"Relatives still bring traditional medicine to patients on admission at the hospital based upon a diviner's advice. Sometimes they say that the patient's illness cannot be treated through orthodox medicine, so the relatives will ask for their discharge against medical advice. In other instances, the diviner's treatment is administered on the blind side of the health professionals in addition to hospital medicines." (Senior Nurse 1)

The preceding outlines the worldview of people in this traditional area, as well as the reasons why they combine diviner and orthodox medicine. According to common belief, a patient's may be confronted with combination of ill health that may require both diviner and orthodox care. Through divination, diviners will be able to discover this phenomenon. In such circumstances, suggestions may be 
offered the relatives-based on what they are able to see secrete-to mix treatments.

One diviner discovered in an in-depth interview that various ailments may necessitate different or a combination of remedies. Those who cannot be totally treated by the diviners are referred to a medical facility for treatment and vice versa.

"Sometimes there are multiple illnesses which cannot be treated at the hospital alone. For example, a patient may be anaemic and dehydrated as well when under spiritual possession. So, I will prepare the herbs for the patient to bathe with and drink to drive away the spirits while the hospital will treat the physical illness. Ever since I settled in this community, I have treated fifteen people (15) of this nature. For example, one woman was sick and was pale. I asked that they send her to the hospital. After that I sent herbs for her to bathe and drink to drive away the jinns". (Diviner Nnye Ndini)

According to the guardians of Dagbon custom and tradition, there are instances where a diviner will beg the family of a patient to bring their love home for traditional care when in their investigations the disease was not designed for "orthodox care" and they are likely to lose the love one if they renege. Because supernatural illnesses are considered spiritual ailments, they cannot be cured with orthodox care. A Dagbon cultural custodian had this to say about the mix of treatments:

"There are several cases when diviner treatments are combined with hospital treatment. Sometimes, the relatives may realize that the illness is supernatural so upon advice the diviner may tell them to bring the patient home for treatment. On the other hand, when relatives run short of money and can no longer pay for the hospital bills, they demand the discharge of the patient against medical advice. I have witnessed that personally. Diviners may employ divination and realize that they must explore orthodox medicine as well for the patient to get healed if the illness is complex or the illness may not be hospital illness but home illness". (Nyab Zaapayim)

In terms of determining the cause of illness and looking for a source of protection and security, the Dagomba employ the use witchcraft, sorcery, and magic to ensure their survival and protection in society. They also employed them as sources for diagnosis to assess whether their clients' misfortunes and fortunes are the consequence of supernatural activities or otherwise.

Thus, in Dagomba family setting, the results of divination may necessitate that patient be discharged occasionally against medical advice. However, our interactions with some of the health experts indicate that all illnesses can be addressed in the health facility. Some people, on the other hand, have views about specific ailments that they consider as unnatural, necessitating a distinct approach to their treatment. In a Gushegu focus group session, one of the participants stated:

When a relative is ill you must consult first through divination to find the cause of the illness and get direction for treatment. The treatment sources may be many depending upon the type of illness. Sometimes, it could be multiple ill- 
nesses that demand both hospital and diviner healing. So, while the patient is at the hospital, a diviner may provide his services. Most diviners are not comfortable with this arrangement.

In-depth interviews with the diviners revealed that the majority of them agreed with focus group discussants that certain illnesses require medical treatment and that they must refer such cases to the health facility. Blood and water transfusions, as well as certain injuries that require surgery, are not addressed by diviners and are referred to health specialists. Some diviners, however, do not believe in the combined treatment because it is impossible to determine who deserves credit. As a result, some diviners were split on whether diviner and hospital care should be combined. During an in-depth interview in Zabzugu, one of the diviners described the following:

"Once a friend came with perforated and pains in the testes. He befriended some one's wife and he was struck by a disease called pagbarigu (evil plot). The hospital authorities could not diagnose it as I did spiritually. However, I asked the hospital authorities to do their part first because we could not treat him concurrently. This is because I do not combine my treatment with the hospital treatment. Sometimes, I will wait for the hospital to discharge the patient first before I offer my treatment. Sometimes, the patient may die by the time of being discharged. I do not combine because when helshe is treated, who do we attribute the credit to? Is it the hospital or me the diviner?" (Diviner Gabsi)

The reasoning in the above focused on allopathic medicine's inadequacy. According to the diviner in question, the ailment described above is simply spiritual. When such a sickness is admitted to the hospital, it necessitates both diviner and allopathic therapy.

\subsection{Diviners' Views Regarding Illnesses They Are Able to Treat}

When questioned if he could treat all types of ailments, one of the diviners (Nye Ndini) stated as follows in an in-depth interview.

"No, I cannot treat all illnesses, because I cannot treat foolishness or stupidity. Or is foolishness or stupidity not an illness?"

The same responses were echoed by other prominent diviners in the Dagbon traditional area, marking an admission of their shortcoming to the effect that it was not all illnesses they could treat. The fact that they sometimes refer clients to a health facility for treatment also attests to their admission of not being able to treat all ailments.

\subsection{Agents of Illness Causation among the Dagomba}

Participants echoed that sickness does not happen in a vacuum. To them, certain agents are responsible for ailment causation, particularly those related to spiritual disorders. The majority of these agents are invisible to ordinary humans unless with spiritual eye. Among the supernatural entities responsible for several illnesses identified by participants included nantoo (a rare bird), alizini, kulkpa- 
riga (spirits), sogu (witchcraft), bag yuli (ancestral spirits), and yal'kura (ancient practices). These are discussed below.

Nantoo (Nantohi plural).

A discussant said this in a focus group discussion,

"Nantoo do not feature in the ordinary everyday language of a Dagomba because its relationship with any event is nothing but illness and death. It looks like a flying animal. Others say it looks like a lizard and, to some, a grasshopper. However, most of the people say it is a flying creature that looks like a bird. It is perceived to cause many problems including ill health and death. When nantoo strikes, it is a diviner who can find the cause of the affliction or calamity". (Discussant number. 3 )

Certain diviners may proceed to administer treatment if they possess an antidote. Nantohi are invisible to the naked eye until they are made visible by a diviner, a healer, or a spiritualist. The illnesses induced by this agent are typically obtained by consuming any food item that is laced with poisonous substance from Nantoo. One diviner said:

" A nantoo can cause illness known Yogu (anthrax). There is a general belief that Yogu produces boils on an infected person and when it does happen the person is entreated to stay away from injection. The consequences of failure to comply could be fatal'.

Another diviner in the study region verified this perspective. He noted that:

"Yogu and boils look similar. Hence, patients with such conditions need not go to the hospital because their conditions have supernatural elements and cannot be handled by a doctor at the hospital. They are best treated by herbalists and diviners who have supernatural therapy for them". (Diviner Suhudoo)

The symptom described above is similar to boils. It is, however, more lethal than boils. According to a discussant during a focus group discussion, "a boil can take on the appearance of Yogu and kill a patient, but Yogu is self-contained and self-destructive". A senior nurse at Yendi Municipal Hospital confirmed the diviner's assertion as follows:

"When patients suspect a condition to be boils or Yogu, they will tell the nurses and doctors that the illnesses forbid injections and that if they inject them, they will die. The victims will not agree to be injected or accept any body piercing object."

\subsection{Sogu (Witchcraft)}

In Dagbani, witchcraft is referred to as "Sogu". The Dagomba believe that some people possess magical abilities that enable them to bewitch or injure others. According to diviners, witches and wizards' equipment may take the appearance of a pot, gourd, shell, or plant seed. A "Sonya" (witch or wizard) possesses the ability to metamorphose into any creature, such a snake, scorpion, cat, wind, or insect. The Dagomba believe that a witch can use any of the tools to inflict illness, deformity, or even death on their victims. They are also said to be capable 
of making women barren or males impotent by spiritually taking out their victims' wombs or testicles. According to several of the diviners interviewed, casting out witchcraft, renders witches powerless. Several of the diviners claimed to have antidotes for witchcraft. According to them, witches/wizards occasionally have the ability to remove a victim's intestines, liver, or stomach and fill the "vacuum" with cotton. Whatever the situation, the diviners asserted their ability to provide treatment. However, according to certain diviners, anyone with the ability to treat victims of witchcraft is himself or herself a witch. This assertion is driven from the belief that a diviner who does not possess witchcraft is himself or herself more likely to be tormented or attacked by the witch or wizard for relieving victims of their attacks.

\subsection{Yal'kura (Vocations)}

Each Dagomba is a member of a vocational group. To name a few, these are fiddlers (gonje nima), barbers (wanzam nima), butchers (nakohi nima), drummers (lunsi), and blacksmiths (machelnima), among others. Each individual is expected to study and practice its kin group's profession. Occasionally, divination will show that the sickness is caused by yal'kura (tradition/culture). That is, when such person or family is said to abandoned its rituals or tremble upon it. When such an illness arises, treatment may include rituals designed to initiate the patient into the vocation. Following that, the individual is expected to obtain the necessary instrument of practice for the vocation and to utilize it in order to set himself or herself free or to use it symbolically on festive occasions to ward off such bad omens or sicknesses that may befall them.

\subsection{Alizini (Air Spirits)}

The alizini is a ghost that is invisible to the naked eye. They exist and coexist alongside humans. They are believed to be capable of causing a variety of ailments, including mental sickness, spirit possession, and epilepsy. They are said to live on mountains, in caves, on the tops of large trees, and in other sacred spiritual locations. Anyone who sees them is supposed to become ill. They travel between $12 \mathrm{p} . \mathrm{m}$. and $12 \mathrm{a} . \mathrm{m}$. They can also take the form of natural entities such as humans, reptiles, rivers, or the wind. Alizini-related disease is referred to as pohim n vubo, which translates as "evil wind has blown over the person."

\subsection{Bag'yuli (Ancestral Spirits)}

Baga yuli refers to the beliefs and rituals surrounding ancestor spirit worship. The Dagomba believe that ancestor spirits have a bigger influence on an individual's existence. They provide the individual with protection, health, and fortune in exchange for good behavior and veneration demonstrated via the offering of sacrifices. The belief is that violating taboos enrages the ancestors, and hence the individual loses protection from his ancestors. Again, failure to make annual or periodic offerings to the ancestors may cause them to take off their 
guiding and protective hand from the family. This may result in family disasters, such as unusual illnesses that are typically diagnosed by diviners, who may also direct rites to be undertaken to placate the ancestors. This is a deeply maintained tradition, particularly among indigenous Dagombas, and is more comparable to idol worship.

\subsection{Management of Life Crisis}

Divination is a daily occurring phenomenon among the Dagombas. In instances such as when one wants to get the right life partner, consummate marriages, to decide a name of a newborn, to embark on a journey, to start a business, among others, most of them will resort first and foremost to divination. In effect, divination defines their whole existence as a people. This study discovered that certain diseases and disasters are frequently treated with suspicion among the Dagomba because they believe that not all illnesses are natural. Rather, some are supernatural or man-made. Finding answers to supernatural or human-caused ailments necessitates the use of diviners to ascertain the true source of illness and to assist the Dagomba man or woman in their quest to manage life crises. Several of these conditions, though not exhaustive, which necessitate the use of diviners to determine courses of action to pursue are addressed in greater detail below.

\subsection{Boil (Narili)}

The Dagomba community as a whole believes that anyone with any type of boil should avoid injections and allopathic treatment. This is because it is considered that hypodermic needles should not be inserted into the body of a person who has a boil; otherwise, the effect may be fatal. This results in the majority of patients refusing injections, even if they are admitted, as boils are associated with lethal Yogu.

A narration from one of the Diviners' regarding illness is reported as follows:

"Boils don't like injection and if a patient refuses advice from a diviner and goes to receive an injection, such a patient is likely to die. That is the reason why we treat boils at home and when they burst, we then advise the patient to go to hospital for cleaning and dressing".

This story highlights the supernatural nature of boils, which precludes the use of injections. According to diviners and village elders, boils may contain the lethal Yogu and victims must avoid injections otherwise the outcome may be fatal.

Divination is a social activity that takes on a ritualistic quality, most often in a religious context. Divination is frequently used as a protective and preventive medicine in some communities and is highly sought after by individuals as a way to know in advance impediments and misfortunes likely to befall them including what to do forestall such occurrences. Or, divination is frequently used as a protective and preventive medicine in some communities and is highly sought after by individuals such as barren women, warriors, and others who fear their adver- 
saries are attempting to harm them through witchcraft, sorcery, and spirit possession. Divination among the Dagombas is daily occurrence and tends to inform most individuals daily activities. For example, one of the diviner-clients stated the following on diviners' consultations on disease causation:

"The very reason why we consult diviners whenever we fall sick or intend to embark on activity is that nothing in this world happens without a cause or a defined right path to fellow. As such, we visit the diviner to find the main cause of the illness or a course of action to chart for success in our undertakings. That is, whether the illness is caused out of the annoyance of the ancestors and if so, how we can overcome such problem or make ease any activity one seeks to undertake. So, it is good to consult diviners before and after the illness is cured so that it will not re-occur again".

The narration demonstrates the significance position divination plays in the study area regarding the management of life crisis and in seeking success in their endeavours. Indeed, divination is employed as a technique for resolving humankind's issues, and in the practice of divination, both curative and preventive medications are made based on the nature of the problem. When confronted with life difficulties, Muslims, Christians, and the educated elites find it exceedingly difficult to withstand the pull of divination. This suggests that the influence of divination in the life experiences of the Dagomba is not limited by one's level of education or religiosity rather, its practice is perverse.

Furthermore, regarding the employment of divination for health-related purposes, the majority of participants in focus group talks agreed that illnesses caused by spirits and ghosts cannot be treated in a hospital because they are spiritual ailments. However, other participants believed that supernatural ailments could be treated in a hospital setting and that they had personally encountered such conditions and sought treatment from diviners and doctors. This means that even individuals who believe spiritual illnesses could be treated at a hospital still make contacts with diviners prior to visiting the health facility. Still, others believed that illnesses caused by spirits and ghosts may be treated at a hospital without consulting a diviner. These group of participants believed that every illness can be cured by a doctor. As a result, this group of discussants had never employed divination in making health decisions.

In summary, a bigger proportion of discussants seek healthcare through divination, despite their belief that ailments caused by spirits and ghosts may be cured in a hospital. According to them, they consult diviners for counsel on the appropriate course of action. Divination is frequently used as a diagnostic tool, according to in-depth interviews with diviners and diviner-clients. It is frequently used to ascertain the causative agents of diseases. Following an in-depth interview with a diviner-client, the following response was elicited:

"At all stages of treatment of an illness, divination is employed to diagnose the cause of sickness. It is when divination is employed that the right therapy can be sought for." 
This narration details the critical role divination plays as a diagnostic therapy both for the management of and in treating patients of all types of illnesses and at all stages of health seeking among the Dagomba.

\section{Discussions}

The study discovered that divination among the Dagombas is a daily routine that they employed to find solutions to existential problems. For instance, in dreams, to ascertain its meaning and possible sacrifices to offer; in misfortunes, to ascertain the cause of the affliction and its remedy; at birth, to ascertain which ancestor is reincarnated; at marriage, to ascertain a suitable woman or man who will flower and bear fruit; at death, to ascertain the cause of death; to establish a business, to ascertain the possible path to success; and so forth. These observations are consistent with Oppong's (1973) findings to the effect that among the Dagombas in Northern Ghana, diviners' consultations are daily routine done to address life crisis. Again, divination is used for a variety of purposes in a variety of societies, for example, Mendonsa (1982) attributed political stability among the Sisala of Ghana's Upper West Region to the practice of divination. Thus, our study highlighted the fact that for the indigenous Dagomba, divination precedes the commencement of important life decisions including those related to the etiology and management of illness and finding solutions to life crisis more generally. This finding is consistent with Mendonsa's (1975) study of the features of Sisala diviners, which concluded that divination is a highly effective strategy for relieving tension in Sisala society.

The study findings establish that certain ailments were seen as spiritual, while others as physical. For instance, erectile dysfunction, poisoning, boils, and the sticking of man's penis in a woman's vagina during intimacy were all considered spiritual ailments. While common cold, malaria, diarrhea, stomachache, and headache were considered to be physical ailments. These findings are consistent with what Azongo and Yidana's (2015) found in their study to the effect that diviners were found to possess spiritual capabilities that enables them to detect common ailments afflicting people and society and to recommend solutions from the invisible world to resolve societal problems. Fratkin (2004), in his article on divination among the Laibon pastoralists in Kenya, asserts that in addition to the diviner's ability to divine and prophesized, some Laibon diviners had additional knowledge and skills to prepare potent medicine that is worn as charms or bracelets to protect against physical dangers such as disease and attack by wild animals or human beings employing sorcery.

Additionally, our research demonstrated that the participants in the study area have four distinct diviner practices that supply the people with the needed services. These included Soothsayers, Jinwariba, AfalMalam, and the Gbanigba, among others. This supports the findings of Nukunya (1969) statement that Afa divination among the ewes imported from Nigeria as a result of West African migration tend to solve indigenous problems. Additionally, it supports 
O'Brien's (2007) conclusions that the Chinese and other societies had a variety of diviners, including I Ching, Numerology, Astrology, and Rune diviners.

Additionally, the study identified disease causative agent among the Dagomba to include the Nantoo, Sogu, Yal kura, Alizini, and Bag'yuli among others. This is consistent with Imperato's (1976) writings on folk medicine and sickness causation in Senegal's Bambara community, where supernatural forces were believed to be the source of illness and misfortune in Sub-Saharan Africa. Imperato (1976) classified these as spirits, ghosts, witchcraft, and sorcery. However, our study specifically identified disease causative agents that are neither spirits, ghosts, witchcraft, nor sorcery, for example, Yal kura and Bag' yuli.

Again, our study discovered that some patients mix diviner and allopathic treatment simultaneously, with the belief that because disease has both physical and spiritual dimensions, it must be treated holistically by combining indigenous with allopathic treatment. Such conceptions tend to shape health seeking behaviors of the people where divination tends to dictate the course(s) of action to follow to remedy life crisis encountered by the Dagombas. Such findings corroborate Osafo's (2014) findings to the effect that patients blend traditional and modern care due to a suspicion of spiritual involvement in their sickness.

Thus, it is important for health providers to comprehend indigenous people's health seeking habits and cosmology. This will require them to acknowledge and accept indigenous communities' perspectives, knowledge, and attitudes towards ill-health and its causative agents. Acceptance of indigenous people conceptualization of health and illness including their health seeking behaviours will create opportunities for dialogue and consensus building geared towards integrating indigenous procedures and practices into mainstream medical practices, where appropriate. This will ensure that all citizens receive holistic health care, through the incorporation of the spiritual component of treatment into the health system. That is, by incorporating the psychosocial model with the biomedical paradigm in order to provide holistic health care to nearly every citizen. The absence of such a practice often results in high levels of unmet health care needs and the consequent refusal of most indigenous people to patronize allopathic health care delivery even at the peril of their lives.

\section{Conclusion}

Allopathic medicine is unable of capturing the supernatural and spiritual components of disease etiology in indigenous civilizations, and so is incapable of providing holistic health care to the people. This is because mainstream medicine has failed to recognize the indigenous civilizations' cosmology as an integral aspect of their cultural traditions. Health care delivery cannot be divorced from indigenous people's cosmology; therefore, if health care delivery is to be holistic, the supernatural component that contributes to sickness etiology must be addressed.

The study discovered that diviners refer patients requiring water and blood 
transfusions, surgery, and insufficient breast milk to hospitals due to a lack of methodology. There was only one exception, in which a diviner claimed to possess a cure for insufficient breast milk and blood. Additionally, the majority of divination services are diagnostic in nature, and their activities may complement rather than compete with mainstream medical therapy. Numerous governments, notably those in South Africa and Ghana, have acknowledged the value of traditional medicine and diviner practice. As a result, traditional medicine has been integrated into Ghana's and South Africa's health care systems.

\section{Conflicts of Interest}

The authors declare no conflicts of interest regarding the publication of this paper.

\section{References}

Annus, A. (2010). Divination and Interpretation of Signs in the Ancient World. Oriental Institute Seminars. Leiden University.

Awalu, B. (2009). The Dagomba Supernatural Beliefs and Care of the Sick. In C. Oppong, P. Antwi, \& K. Waerness (Eds.), Care of the Seriously Sick and Dying. Perspectives from Ghana (pp. 211-227). Allkopi.

Aydin, R., \& Aktaş, S. (2021). An Investigation of Women's Pregnancy Experiences during the COVID-19 Pandemic: A Qualitative Study. International Journal of Clinical Practice, 75, e14418. https://doi.org/10.1111/ijcp.14418

Azongo, T. B., \& Yidana, A. (2015). Spiritual Diagnostic Laboratory: The Role of Diviners in the Management and Resolution of Life Crises. American Journal of Sociological Research, 5, 7-13.

Bierlich, B. (1994). The Powers of Medicines, Notions and Practices of Health and Illness among the Dagomba of Northern Ghana. University of Cambridge.

Bierlich, B. (2007). The Problem of Money: African Agency and Western Medicine in Northern Ghana. Berghahn Books.

Braun, V., \& Clarke, C. (2014). What Can “Thematic Analysis" Offer Health and Wellbeing Researchers? International Journal of Qualitative Studies on Health and Well-Being, 9, 26152. https://doi.org/10.3402/qhw.v9.26152

Clarke, V., \& Braun, V. (2018). Using Thematic Analysis in Counselling and Psychotherapy Research: A Critical Reflection. Counselling and Psychotherapy Research Journal, 18, 107-110. https://doi.org/10.1002/capr.12165

Clarke, V., Braun, V., Terry, G., \& Hayfield, N. (2019). Thematic Analysis. In P. Liamputtong (Ed.), Handbook of Research Methods in Health and Social Sciences (pp. 843-860). Springer. https://doi.org/10.1007/978-981-10-5251-4_103

Fortes, M. (1987). Religion, Morality and the Person: Essays on Tallensi Religion. Cambridge University Press. https://doi.org/10.1017/CBO9780511557996

Fratkin, E. (2004). The Laibon Diviner and Healer among Samburu Pastoralists of Kenya. In M. Winkelman, \& P. Peek (Eds.), Divination and Healing (pp. 207-226). The University of Arizona Press.

Homan, G. C. (1974). “Social Behaviour”. Its Elementary Forms (Revised ed.). Harcourt Brace Jovanovich Inc.

Imperato, P. J. (1976). African Folk Medicine: Practices and Belief of the Bambara and 
Other Peoples. York Press.

Kumekpor, T. (2002). Research Methods and Techniques of Social Research. SonLife Publishers.

Mendonsa, E. L. (1982). The Politics of Divination. A Processual View of Reaction to Illness and Deviance among the Sisala of Northern Ghana. University of California Press.

Mendonsa, E. L. (1975). Characteristics of Sisala Diviners. Institute of African Studies Library, University of Ghana. https://doi.org/10.1515/9783110805840.179

Meyer, B. (1999). Translating the Devil: Religion and Modernity among the Ewe in Ghana. Edinburgh University Press.

Ngutor, S., Lumun, A., \& Terwase, I. (2013). The Role of Divination in Treatment of Disease in Kwande Local Government Area of Benue State, Nigeria. International Journal of Humanities and Social Science Invention, 2, 21-29.

Nukunya, G. K. (1969). Afa Divination in Anlo: A Preliminary Report. Research Review, 5, 9-26.

Nukunya, G. K. (2013). Tradition and Change in Ghana (7th ed.). Ghana Universities Press.

Nyabwari, B. G. (2014). The Impact of Magic and Witchcraft in the Social, Economic, Political and Spiritual Life of African Communities. International Journal of Humanities Social Sciences and Education (IJHSSE), 1, 9-18.

O’Brien, P. (2007). Divination: Sacred Tools for Reading the Mind of God. Visionary Networks Press.

Oppong, C. (1973). Growing Up in Dagbon. Ghana Publishing Corporation.

Osafo, J. (2014). Psychology and Health in Ghana. In C. Akotia, S. Charity, \& C. Mate-Kole (Eds.), Contemporary Psychology, Readings from Ghana (pp. 111-130). Tema.

Senah, K. A. (1992). "You Devil, Go Away from Me": Some Ethnographic Commends on Evil Diseases in a Ghanaian Village. Etnofoor Jaargang, 5, 129-145. 